\title{
Effect of enhanced biosecurity and selected on-farm factors on Campylobacter colonization of chicken broilers
}

\author{
M. GEORGIEV ${ }^{1 *}$, W. BEAUVAIS ${ }^{2}$ AND J. GUITIAN ${ }^{2}$ \\ ${ }^{1}$ The Food Standards Agency, London, UK \\ ${ }^{2}$ The Royal Veterinary College, London, UK
}

Received 4 April 2016; Final revision 3 October 2016; Accepted 7 October 2016; first published online 22 November 2016

\section{SUMMARY}

Human campylobacteriosis is the most commonly reported gastrointestinal bacterial infection in the EU; poultry meat has been identified as the main source of infection. We tested the hypothesis that enhanced biosecurity and other factors such as welfare status, breed, the practice of partial depopulation and number of empty days between flocks may prevent Campylobacter spp. caecal colonization of poultry batches at high levels (>123000 c.f.u./g in pooled caecal samples). We analysed data from 2314 poultry batches sampled at slaughter in the UK in 2011-2013. We employed random-effects logistic regression to account for clustering of batches within farms and adjust for confounding. We estimated population attributable fractions using adjusted risk ratios. Enhanced biosecurity reduced the odds of colonization at partial depopulation [odds ratio (OR) $0 \cdot 25,95 \%$ confidence interval (CI) $0 \cdot 14-0 \cdot 47$ ] and, to a lesser extent, at final depopulation (OR 0.47, 95\% CI 0.25-0.89). An effect of the type of breed was also found. Under our assumptions, approximately $1 / 3$ of highly colonized batches would be avoided if they were all raised under enhanced biosecurity or without partial depopulation. The results of the study indicate that on-farm measures can play an important role in reducing colonization of broiler chickens with Campylobacter spp. and as a result human exposure.

Key words: Biosecurity, Campylobacter, chicken, epidemiology.

\section{INTRODUCTION}

Campylobacter spp. are the most commonly reported gastrointestinal bacterial pathogen in humans in the EU, responsible for an estimated cost of $€ 2 \cdot 4$ billion a year $[1,2]$.

Campylobacter jejuni is the species most frequently identified in human cases. The course of disease varies in severity from 3 to 6 days of diarrhoea to development of complications, including pancreatitis, arthritis

\footnotetext{
* Author for correspondence: Mr M. Georgiev, Food Standards Agency, 125 Kingsway, London, UK.

(Email: milen.georgiev@foodstandards.gsi.gov.uk)
}

and neurological disorders [3]. Poultry meat is considered the main source of human campylobacteriosis [4], and the intestines of commercial broilers (Gallus gallus) are often colonized [5, 6]. Microbial genetic data has provided further evidence of linkages between Campylobacter spp. strains in poultry and humans [7, 8]. The European Food Safety Authority (EFSA) has estimated that $20-30 \%$ of campylobacteriosis in humans may be attributed to the consumption of broiler meat, and $50-80 \%$ of all human cases of $C$. jejuni to the chicken reservoir as a whole [9]. An EFSA survey across 26 EU countries and two other countries in Europe in 2008 [10] showed an average of $71 \cdot 2 \%$ and ranged from a minimum of $2 \cdot 0 \%$ to a 
maximum of $100 \cdot 0 \%$ poultry batches testing positive at slaughter.

The pathogen may be introduced from the environment $[11,12]$ to poultry houses via different routes including houseflies [13], farmers' boots during daily operations or staff during partial depopulation [14]. Further horizontal transmission occurs from infected individuals to the surrounding environment and to other susceptible birds [15], and colonization (presence of Campylobacter spp. in birds' intestines) of the entire flock occurs within a matter of a few days [16]. Theoretically, enhanced biosecurity in commercial farms could reduce the risk of batch colonization. However, there is limited empirical evidence that supports this hypothesis. As shown by an extensive literature review on the subject [15], study results are often questionable due to differences in implementation and poor study design and analysis. Besides the enhancement of biosecurity, several 'on-farm' strategies have been proposed to reduce the risk of flock colonization and spread including chlorinated drinking water [17], bacteriophage therapy [18] and bacteriocins [19] or the use of probiotics [20] and vaccination [21]. However, many of those are still currently in development or considered not feasible. Evidence to assess the rationale of implementing feasible on-farm interventions such as enhancement of biosecurity is therefore urgently needed.

Between September 2011 and August 2013, the UK poultry industry implemented a plan of enhanced biosecurity [i.e. operating in each poultry house (shed) as a biosecure unit, using protective clothes and shedspecific equipment in addition to standard procedures] on a number of 'model farms'.

We present an analysis of these data, including comparison of the levels of Campylobacter caecal colonization in batches raised in 'model farms' under enhanced biosecurity with control batches from farms with 'standard biosecurity'.

\section{MATERIALS AND METHODS}

\section{Study population and data sources}

We investigated Campylobacter colonization in broiler chickens slaughtered in the UK between 1 September 2011 and 31 August 2013.

\section{Selection of 'model' farms}

Sixteen farms were selected by the industry as 'model' examples, where a new protocol for enhanced biosecurity was implemented from August 2011. Although no formal probabilistic selection of candidate farms for enhancement of biosecurity was conducted, the 16 farms (denoted with alphabetic characters from $\mathrm{A}$ to $\mathrm{O}$ ) were considered to apply standard production practices as in other broiler farms in the UK, were geographically dispersed and belonged to three different companies. Farm staff were trained and operated each poultry house (shed) as a biosecure unit using dedicated tools, garments and footwear, protective clothes and shed-specific equipment, including for garbage and collection of dead birds, in addition to implementing standard procedures and highlighting the importance of having specific entry and exit procedures with washing and disinfection facilities for each poultry house. After the project, the procedures of enhanced biosecurity were shared with all farmers and a visual guide was prepared by the Food Standards Agency (FSA) and the National Farmers Union (NFU; http://www. nfuonline.com/fsa-infographic-campylobacter-biosecur ity-cmyk-v3-lh-250615_not-signed-o/).

Further details on applied biosecurity measures in model farms are available in Supplementary Tables S1 and S2. Model farms were located in England, Wales, Scotland and Northern Ireland and linked to different retailers. The number of sheds ranged from 1 to 12 per farm.

\section{Selection of 'model' batches}

Batches of chickens (birds which had been grown in the same shed and delivered to a slaughterhouse on one single day) were the study unit. Data were collected for 1749 batches from model farms. Batches were selected so that all sheds would be sampled during the study. For purpose of data analysis, the 2-year study period was divided into 16 intervals of 45 days and each batch allocated to one of the 16 intervals based on the date when it was sent to the slaughterhouse.

\section{Selection of control farms and batches}

Three groups of control batches were investigated, as follows:

Broilers originated from different farms where standard biosecurity was applied (i.e. compliance with the Red Tractor assurance scheme; http://assurance.redtractor.org.uk/).

(1) 'Control batches l' were selected in four poultry processing plants. Information on the number of farms and origin of the batches was not available for analysis. Between April 2012 and October 2013, 366 batches were selected based on subjective 
assessments by the company veterinarians as batches of similar age, kept under similar conditions and slaughtered in the same week as the batches from farms with enhanced biosecurity.

(2) 'Control batches 2' originated from five farms selected to match five of the model farms for all factors except biosecurity. A total of 30 batches were selected from these farms matched by week of slaughter to the corresponding 'model' batches.

(3) 'Control batches 3' originated from five farms selected to match five model farms (A, B, C, D, E) for all factors with the exception of biosecurity. Information was collected for 136 batches in this group. Chickens were tested at thinning (partial depopulation) and also at final depopulation. We did not combine the batches from control farms 3 with those in control farms 2 as the investigation period was different.

\section{Sample collection and laboratory testing}

For each of the study batches, samples were taken from the caeca of five birds in the batch at the beginning of slaughter at the time of evisceration and pooled as a single sample. Samples were also taken from neck skins of three birds in the batch immediately after chilling at the end of the slaughter line and pooled as a single sample. The birds' carcasses were selected in a non-systematic way. All samples were tested to enumerate Campylobacter spp. without further speciation according to the agreed standards of International Organization for Standardization (ISO) ISO10272-2 2006. The methodology was considered to be well established and was harmonized between the laboratories used by the three poultry companies involved in the study. Results therefore allow comparison between levels in caeca and neck skin and, further, with data from ongoing national monitoring in slaughterhouses in the UK.

\section{Batch-level risk factors}

For batches grown in 'model farms', information was obtained on other husbandry factors which could potentially have an influence upon colonization of broilers, namely:

Welfare status (data available for all 1749 batches), defined as:

- 'Higher': broilers can be reared in the flock up to $30 \mathrm{~kg} / \mathrm{m}^{2}$, with added enrichments (play-bales, perches and artificial play-objects), the glass area of the windows is a minimum of $1-3 \%$ of the floor area, according to 'Red Tractor' standards; or

- 'Freedom Food': stocking density is up to $30 \mathrm{~kg} / \mathrm{m}^{2}$ and rearing of a slow-growing hybrid (JA 87) is required; or

- 'Standard': maximum stocking density is $>30 \mathrm{~kg} / \mathrm{m}^{2}$.

Number of empty days between flocks (available for 1693 batches, $96 \cdot 8 \%$ ).

Number of days from partial depopulation (thinning) to the end of the production cycle (available for 1568 batches of the 1654 batches where thinning was practised, $94 \cdot 8 \%$ ).

Type of broiler hybrid (available for 1745 batches, $99 \cdot 8 \%)$.

\section{Data analysis}

In our analysis the outcome was a binary variable: based on caeca results, batches were classified as highly colonized $v s$. not highly colonized. To classify a batch as 'highly colonized' based on caeca results we used the threshold value that corresponds with a neck skin count $>3 \log _{10}$, which is used as the high-risk threshold related to public health, jointly accepted by FSA and the poultry industry. The derivation of this value is as follows.

Defining a threshold for high levels of Campylobacter colonization

We examined the frequency distributions of the counts of Campylobacter spp. in caeca and neck skin samples at different percentiles (1st, 5th, 10th, 25th, 35th, 50th, 65th, 75th, 90th, 95th, 99th, and the maximum values). In each of the specified percentiles, we calculated the difference between results in caeca and neck skin using a $\log _{10}$ scale. The $95 \%$ confidence interval (CI) for the resulting distribution of these differences was obtained. The value at the lower confidence limit for this difference was added to the level of $3 \log _{10}$ of neck skin colonization. This was done because of the interest in defining a high-risk threshold based on caeca results.

\section{Identification of factors associated with high levels of Campylobacter colonization}

The risk of being a highly colonized batch was estimated for: batches raised under enhanced biosecurity vs. batches raised under standard biosecurity (controls); batches harvested at thinning (partial depopulation) vs. 
at the end of the cycle (depopulation); batches composed of different hybrids (Cobb 500, Cobb 500 \& Ross 308, Ross 308, Ross 708, JA 87); batches with different empty days before the start of the cycle (1-7, $8-14,15-21,22-47$ days); batches with different number of days between thinning and depopulation: $(1-3$, $4-6,7-9,10-12,13-18$ days); batches for which welfare was 'standard', 'higher' or 'freedom food' and batches which were slaughtered at 90-day intervals between 1 September 2011 and 31 August 2013.

Univariate analysis was first carried out, followed by multivariate analysis to explore the combined effect of multiple factors on the odds of colonization at high levels (>123000 c.f.u./g). Four multivariate models were built.

(1) 'Biosecurity model'. A random-effects logistic model was used to compare the odds of colonization between batches from farms with enhanced biosecurity (model batches) and batches from farms with standard biosecurity (control batches 1 ). The model controlled for the potential effect of harvest occasion (thinning $v s$. depopulation) and season and accounted for the fact that batches from the same farm may be more 'similar' than batches from different farms (i.e. within-farm clustering).

(2) 'Risk factors within high biosecurity farms model'. A random-effects logistic model was used to compare the odds of colonization between batches at different harvest occasion while controlling for the potential effect of type of hybrid, empty days between flocks and season. As for model 1, model 2 also accounted for within-farm clustering. Only batches from model farms were used in this model as data on husbandry factors were only available for model farms.

(3) 'Thinning practice model'. A random-effects logistic model was used to compare the odds of colonization at depopulation between batches where partial depopulation was conducted and batches without partial depopulation. This model controlled for potential effect of season and within-farm clustering and was limited to model batches only.

(4) 'A Company's five-farms model'. Conditional logistic regression was used to compare the odds of colonization between batches from five farms (A-E) with enhanced biosecurity and batches from five farms with standard biosecurity (control batches 3). The model controlled for harvest occasion and season, and accounted for within-farm clustering.
Control batches 2 were not included in the multivariate models due to the data for only 16 batches at thinning and 14 at depopulation.

\section{Estimation of population attributable fractions (PAFs)}

We utilized the estimates of the strength of the association between (i) enhanced biosecurity, (ii) partial depopulation and (iii) hybrid type with odds of colonization at high levels (obtained from the models mentioned above), to estimate the proportion of heavily colonized batches that could be attributed to each of these factors (PAFs). The proportion of heavily colonized batches that would be prevented was estimated under the following different scenarios: (i) enhancement of biosecurity, (ii) elimination of the practice of thinning, and (iii) use of low-risk hybrid types. Assumptions were made as to the proportion of the total broiler population currently 'exposed' to each of the three individual factors (i.e. all flocks are under standard biosecurity, $30 \%$ of the flocks are of hybrids with low colonization results and $90 \%$ of batches are thinned; these are believed to be reasonable values for the UK broiler population).

The odds ratios (ORs) obtained from the regression models were converted to adjusted relative risk (aRR) values [22] and used to estimate the PAF [23, 24].

$$
\begin{aligned}
\mathrm{aRR}= & \mathrm{OR} /[(1-\text { risk at baseline }) \\
& \left.+\left(\text { risk at baseline }{ }^{*} \mathrm{OR}\right)\right] .
\end{aligned}
$$

PAF values were estimated as

$\mathrm{PAF}=\mathrm{Pd}^{*}(\mathrm{aRR}-1) / \mathrm{aRR}$,

where Pd is the percentage of batches exposed to factors among highly colonized batches.

\section{Ethical standards}

The authors assert that all procedures contributing to this work comply with the ethical standards of the relevant national and institutional guides.

\section{RESULTS}

The identified $95 \%$ CI 2.09-3.68 of differences between caeca and neck skin results on the $\log _{10}$ scale suggests that the batches positive in neck skin $>1000$ c.f.u./g $\left(3 \log _{10}\right)$ were colonized in caeca with results of at least $5.09 \log _{10}$.

Overall, $58 \cdot 6 \%$ of all the studied batches were heavily colonized (>123000 c.f.u./g in pooled caecal 


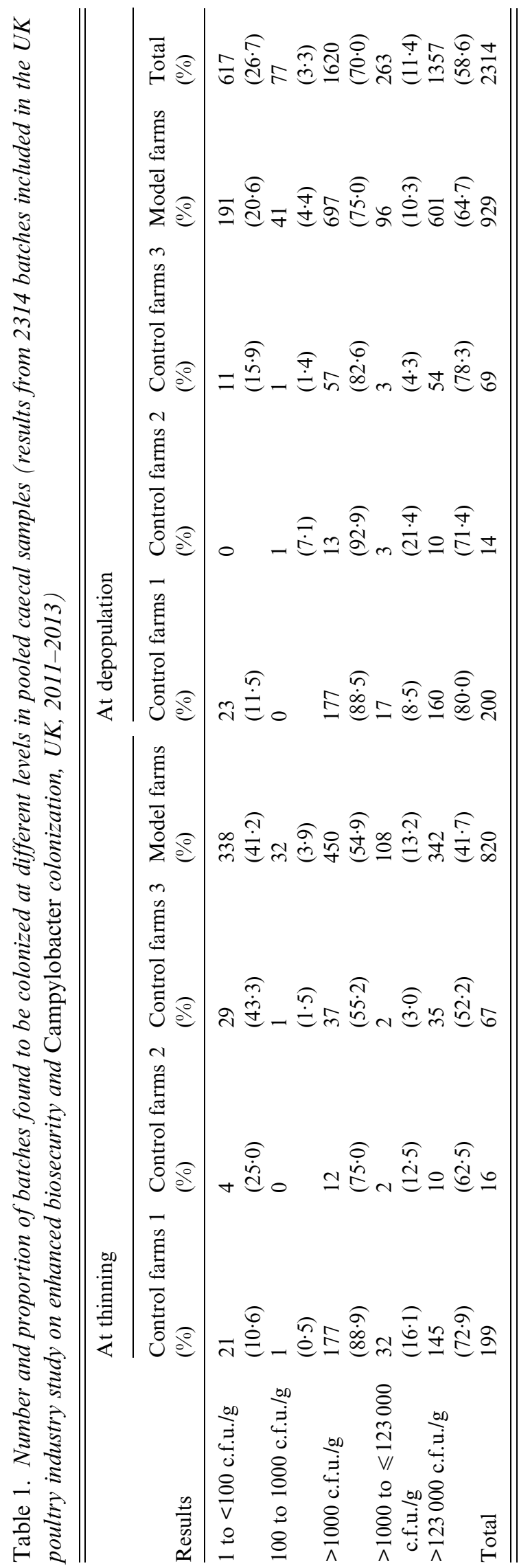

samples) (Table 1). The proportion of colonized batches exhibited a seasonal pattern, with peaks during the summer period (Figs 1 and 2).

\section{Univariate analysis}

In the univariate analysis, all the factors under study, except the poultry company of origin, were significantly $(P<0.05)$ associated with colonization at high levels (Table 2).

\section{Multivariate analysis}

\section{Biosecurity model}

Enhancement of biosecurity modified the effect of harvesting at thinning $v s$. at depopulation and vice versa (Table 3). Enhancement of biosecurity reduced the odds of colonization when harvesting took place at thinning $(25 \%$ of the odds of infection of a standard biosecurity batch harvested at thinning) but the effect was markedly reduced when harvesting took place at the end of the cycle ( $47 \%$ of the odds of a standard biosecurity batch harvested at depopulation). A high proportion $(72.9 \%)$ of batches raised under standard biosecurity was already colonized at the time of thinning. Only $41.7 \%$ of batches raised under enhanced biosecurity were colonized at thinning. This proportion increased to $64.7 \%$ when harvesting took place at depopulation.

The model results confirm the role of season. The likelihood of batch colonization was higher in the summer.

\section{Risk factors within high-biosecurity farms model}

In farms with enhanced biosecurity, batches at depopulation had three times higher odds of colonization than batches at thinning (Table 4). Compared to the baseline hybrid (Ross 308), batches of Cobb 500 had $53 \%$ of the odds of high colonization. The mixed Cobb 500 \& Ross 308 had three times higher odds of colonization compared to Ross 308. The sheds that were kept empty for up to 1 week were less likely to produce highly colonized batches (OR $0 \cdot 69,95 \%$ CI $0 \cdot 49-0 \cdot 96$ ) than batches grown after a 1- to 2-week empty period. An empty period between flocks of $>3$ weeks was associated with three times higher odds of colonization than the baseline group of 1-2 weeks empty period. Batches which had experienced a short period (1-3 days) between thinning and depopulation had half the odds of colonization $>123000$ c.f.u./g compared to batches experiencing a 


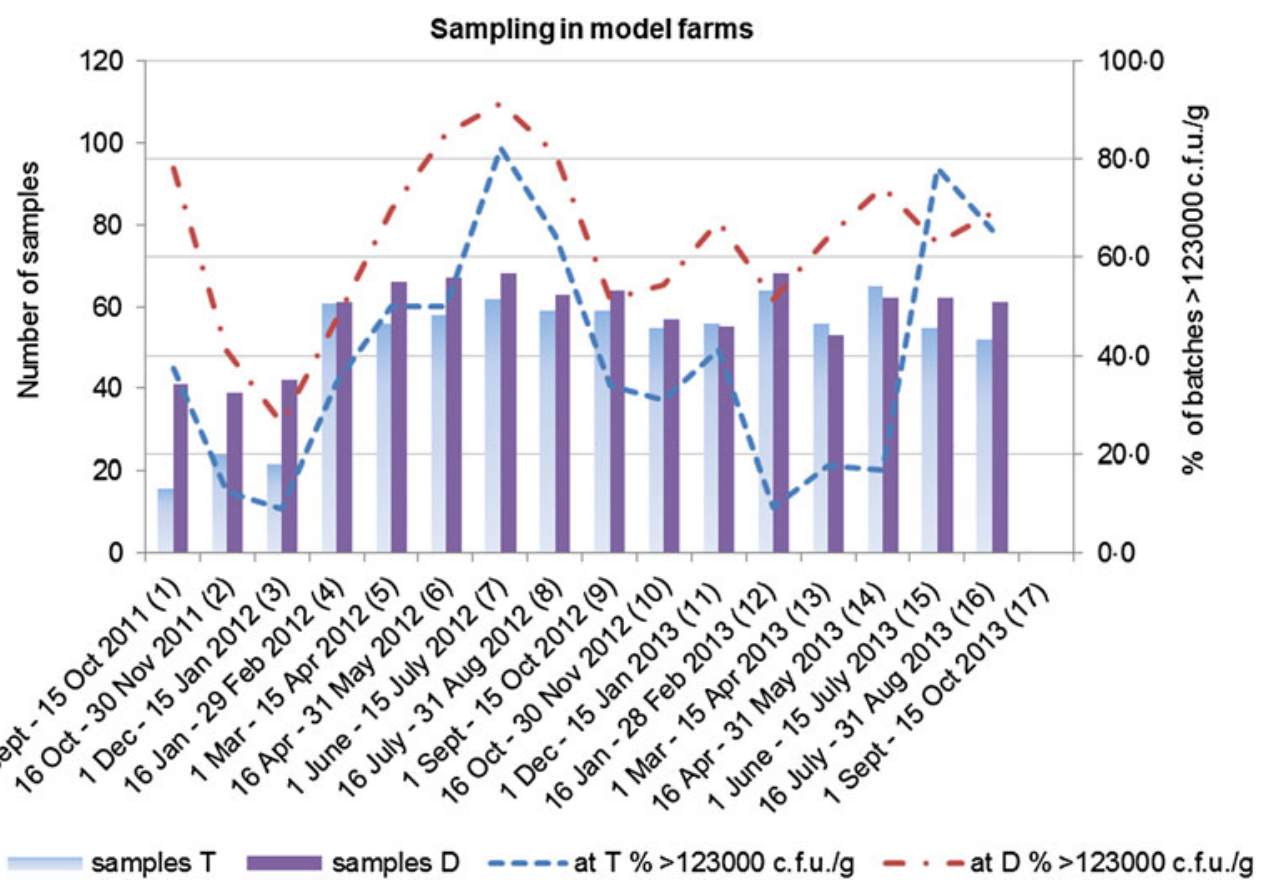

Fig. 1. Seasonal variation in Campylobacter colonization of batches in model farms. Colonized batches are those with $>123000$ c.f.u./g in pooled faecal samples obtained either at thinning (T) or at depopulation (D).

period of 7-9 days. There is no statistical evidence to differentiate the results of Ross 308 from JA 87, Ross 708 or the mix of Cobb $500 \&$ Ross 308 .

\section{Thinning practice model}

In farms with enhanced biosecurity, flocks that were thinned had more than twice $(2.63)$ the odds of colonization at depopulation than flocks that were not thinned (Table 5).

\section{A company's five-farms model}

The results of comparing the odds of colonization in batches from five model farms matched to batches from the third group of control farms are presented in Table 6. The results confirmed the protective effect of enhanced biosecurity on batch colonization, the increased odds of colonization at depopulation and the seasonality of batch colonization.

\section{Sensitivity analysis}

In order to assess the impact of the chosen cut-off, we repeated all univariate and multivariate analyses using a lower threshold (1000 c.f.u./g) for classification of high-colonization based on caeca results. The result of this different cut-off was that $11.4 \%$ of batches were re-classified as highly colonized. However, we obtained very similar results for the risk factor analysis.

\section{PAFs}

Under the assumptions that identified risk factors have a causal association with the colonization of poultry batches and that the above estimates provide an unbiased measure of the association between the studied exposures and colonization, the following estimates were made:

If all batches in the UK were raised under enhanced biosecurity an estimated $32 \cdot 0 \%(95 \%$ CI $16 \cdot 0-41 \cdot 0)$ of colonized batches in the population would be avoided (Fig. 3). This is under the assumption that no UK farms operate under enhanced biosecurity (with the exception of model farms in this study) in 2013.

If none of the batches were subject to thinning then an estimated $33 \cdot 0 \%(95 \%$ CI $14 \cdot 0-44 \cdot 0)$ of highly colonized batches could be avoided (Fig. 4). This value assumes that thinning is currently practised in $90 \%$ of batches (as observed in this study).

If all batches were of the hybrid types associated with a lower risk, between $4.0 \%$ and $27 \cdot 0 \%$ of batch colonization could be prevented (Fig. 5). In this study, more than $70.0 \%$ of batches were from those hybrids associated with higher risk of colonization. 

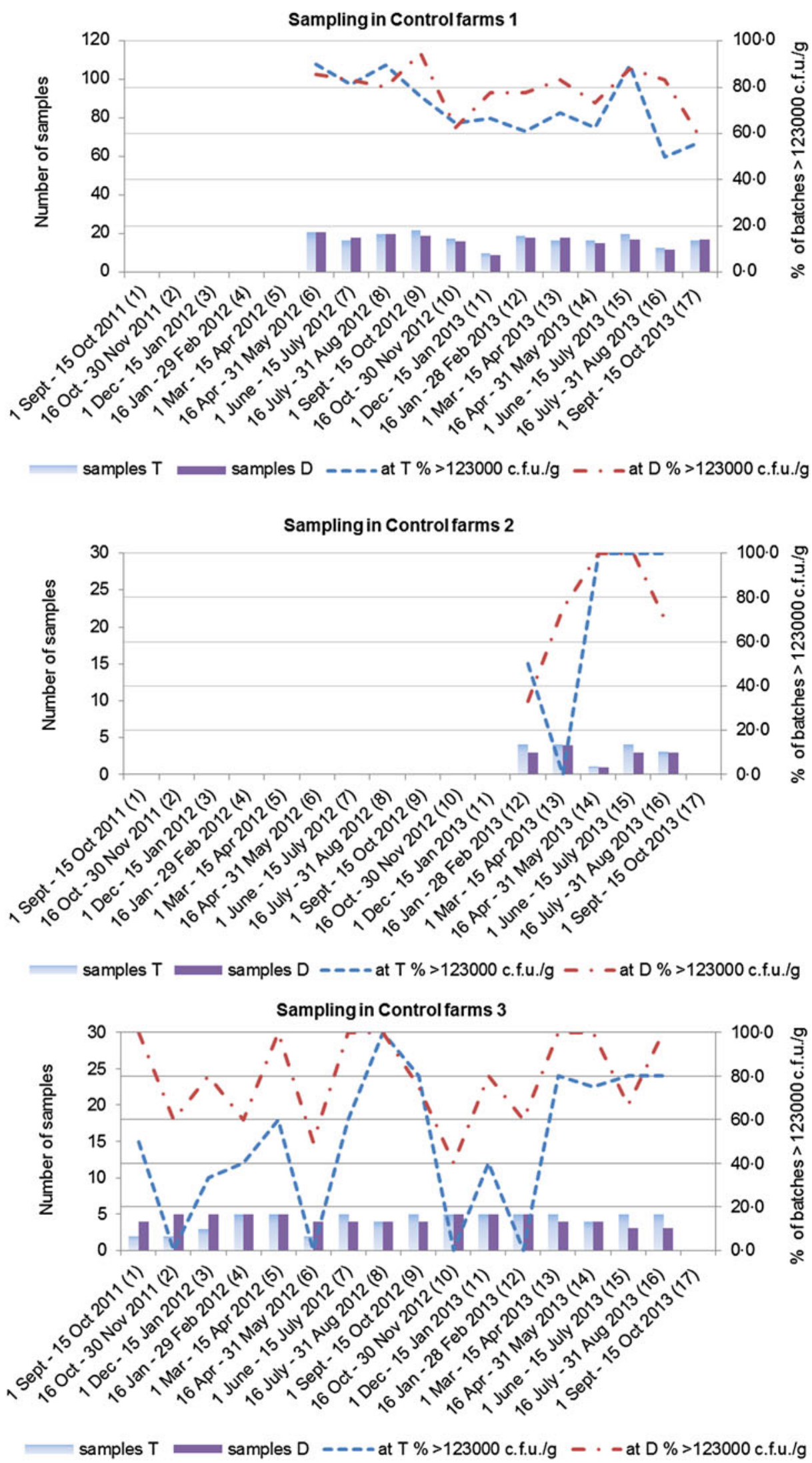

Fig. 2. Seasonal variation in Campylobacter colonization of batches in control farms. Colonized batches are those with $>123000$ c.f.u./g in pooled faecal samples obtained either at thinning (T) or at depopulation (D). 
Table 2. Univariate associations between potential risk factors and Campylobacter spp. colonization at high level (>123000 c.f.u.lg in pooled caecal samples; results from 2314 batches included in the UK poultry industry study on enhanced biosecurity and Campylobacter colonization, UK, 2011-2013)

\begin{tabular}{|c|c|c|c|c|}
\hline Variable & Categories & $\begin{array}{l}\text { No. }(\%) \text { of batches } \\
>123000 \text { c.f.u./g }\end{array}$ & $\begin{array}{l}\text { No. of batches } \\
\leqslant 123000 \text { c.f.u./g }\end{array}$ & $P$ value $\left(\chi^{2}\right)^{*}$ \\
\hline \multirow[t]{2}{*}{ Harvest occasion } & Thinning & $532(48 \cdot 3)$ & 570 & \multirow[t]{2}{*}{$<0 \cdot 001$} \\
\hline & Depopulation & $824(68 \cdot 0)$ & 388 & \\
\hline \multirow[t]{4}{*}{ Biosecurity } & Model farms & $943(53 \cdot 9)$ & 806 & \multirow[t]{4}{*}{$<0 \cdot 001$} \\
\hline & Control farms 1 & $304(76 \cdot 2)$ & 95 & \\
\hline & Control farms 2 & $20(66 \cdot 7)$ & 10 & \\
\hline & Control farms 3 & $89(65 \cdot 4)$ & 47 & \\
\hline \multirow[t]{3}{*}{ Welfare in model farms } & Standard & $588(53 \cdot 5)$ & 512 & \multirow[t]{3}{*}{$0 \cdot 038$} \\
\hline & Higher & $305(53 \cdot 0)$ & 271 & \\
\hline & Freedom food $\dagger$ & $50(68 \cdot 5)$ & 23 & \\
\hline \multirow[t]{5}{*}{ Hybrid in model farms } & Cobb 500 & $183(48 \cdot 4)$ & 195 & \multirow[t]{5}{*}{$0 \cdot 001$} \\
\hline & Cobb 500 \& Ross 308 & $18(72 \cdot 0)$ & 7 & \\
\hline & Ross 308 & $613(54 \cdot 5)$ & 511 & \\
\hline & Ross 708 & $69(50 \cdot 4)$ & 68 & \\
\hline & JA 87 & $57(70 \cdot 4)$ & 24 & \\
\hline \multirow{5}{*}{ Empty days in model farms } & 1-7 days & $233(51 \cdot 2)$ & 218 & \multirow[t]{5}{*}{$<0 \cdot 001$} \\
\hline & $8-14$ days & $585(54 \cdot 4)$ & 491 & \\
\hline & 15-21 days & $57(48 \cdot 3)$ & 61 & \\
\hline & $22-47$ days & $35(72 \cdot 9)$ & 13 & \\
\hline & n.a. & $446(71 \cdot 8)$ & 175 & \\
\hline \multirow{6}{*}{$\begin{array}{l}\text { Days from thinning to depopulation } \\
\text { in model farms }\end{array}$} & 1-3 days & $143(48 \cdot 8)$ & 150 & \multirow[t]{6}{*}{$<0 \cdot 001$} \\
\hline & 4-6 days & $344(54 \cdot 4)$ & 288 & \\
\hline & 7-9 days & $215(58 \cdot 0)$ & 156 & \\
\hline & $10-12$ days & $99(57 \cdot 2)$ & 74 & \\
\hline & 13-18 days & $60(60 \cdot 6)$ & 39 & \\
\hline & n.a. & $495(66 \cdot 4)$ & 251 & \\
\hline \multirow{4}{*}{$\begin{array}{l}\text { Processors dealing with batches of } \\
\text { control farms } 1\end{array}$} & Q & $54(77 \cdot 14)$ & 16 & \multirow[t]{4}{*}{$0 \cdot 088$} \\
\hline & $\mathrm{R}$ & $58(79 \cdot 5)$ & 15 & \\
\hline & $\mathrm{S}$ & $99(81 \cdot 8)$ & 22 & \\
\hline & $\mathrm{T}$ & $93(68 \cdot 9)$ & 42 & \\
\hline \multirow{2}{*}{$\begin{array}{l}\text { Practice of partial depopulation } \\
\text { in model farms }\end{array}$} & Thinning had been practised & $555(66 \cdot 6)$ & 279 & \multirow[t]{2}{*}{$<0 \cdot 001$} \\
\hline & Thinning had not been practised & $46(48 \cdot 4)$ & 49 & \\
\hline
\end{tabular}

n.a., Not available.

$* \chi^{2}$ test on $(\mathrm{r} \times \mathrm{c})$ tables.

$\dagger$ In addition to the specific welfare conditions the category requires rearing of hybrid JA 87.

Interventions against different factors could be introduced simultaneously. We estimate that $\sim 30 \%$ $(95 \%$ CI $13 \cdot 0-37 \cdot 0)$ of highly colonized batches could be avoided in a hypothetical scenario of successfully enhancing biosecurity in half of the batches, avoiding thinning in a third of batches in which it is currently practised and shifting to hybrids with a lower risk of colonization in at least $30.0 \%$ of the batches being at high risk.

\section{DISCUSSION}

This study analysed the impact of enhanced biosecurity measures and selected husbandry factors on
Campylobacter colonization of broiler batches. We proposed a threshold for high colonization in caeca (>123000 c.f.u./g) by correlating caecal and neck skin results and considering the established cut-off for high-risk group in neck skin.

\section{Effect of biosecurity}

The results of the analyses undertaken provide strong evidence that enhanced biosecurity has a protective effect on batch colonization at thinning, reducing the odds of high colonization by between $53.0 \%$ and $86.0 \%$. At the time of depopulation, the effect of increased biosecurity is considerably lower. The strong 
Table 3. Results of a random-effects logistic regression (regression model 1 'biosecurity model') of enhanced biosecurity, harvest occasion and sampling period on batch colonization (defined as $>123000$ c.f.u.Ig in pooled caecal samples). Results from a total of 1687 batches sampled between 16 April 2012 and 31 August 2013 included in the UK poultry study on enhanced biosecurity and Campylobacter colonization, UK, 2011-2013

\begin{tabular}{|c|c|c|}
\hline Factors & OR $(95 \% \mathrm{CI})$ & $P$ value \\
\hline \multicolumn{3}{|l|}{ Biosecurity } \\
\hline Standard (control farms 1) & $1 \cdot 00$ & \\
\hline Enhanced (model farms) & $0 \cdot 25(0 \cdot 14-0 \cdot 47)$ & $<0.001$ \\
\hline \multicolumn{3}{|l|}{ Harvest occasion } \\
\hline Thinning & $1 \cdot 00$ & \\
\hline Depopulation & $1 \cdot 68(0 \cdot 93-3 \cdot 03)$ & $0 \cdot 086$ \\
\hline \multicolumn{3}{|c|}{ Interaction between biosecurity and harvest occasion } \\
\hline Model farm and depopulation & $1 \cdot 85(0 \cdot 98-3 \cdot 50)$ & $0 \cdot 059$ \\
\hline \multicolumn{3}{|l|}{ Effect of depopulation } \\
\hline In model farm & $3 \cdot 10(2 \cdot 43-3 \cdot 96)$ & \\
\hline In control farms 1 & $1.68(0.93-3 \cdot 03)$ & \\
\hline \multicolumn{3}{|l|}{ Effect of enhanced biosecurity } \\
\hline At thinning & $0 \cdot 25(0 \cdot 14-0 \cdot 47)$ & \\
\hline At depopulation & $0 \cdot 47(0 \cdot 25-0 \cdot 89)$ & \\
\hline \multicolumn{3}{|l|}{ Sampling period } \\
\hline 16 Apr.-31 May 2012 & $3 \cdot 56(2 \cdot 26-5 \cdot 61)$ & $<0 \cdot 001$ \\
\hline 1 June-31 Aug. 2012 & $5 \cdot 91(4 \cdot 00-8 \cdot 73)$ & $<0 \cdot 001$ \\
\hline 1 Sept. -30 Nov. 2012 & $1 \cdot 21(0 \cdot 86-1 \cdot 72)$ & $0 \cdot 278$ \\
\hline 1 Dec.-28 Feb. 2013 & $1 \cdot 00$ & \\
\hline 1 Mar.-31 May 2013 & $1 \cdot 09(0 \cdot 77-1 \cdot 54)$ & $0 \cdot 619$ \\
\hline 1 June-31 Aug. 2013 & $3 \cdot 04(2 \cdot 11-4 \cdot 38)$ & $<0 \cdot 001$ \\
\hline Constant & $1 \cdot 60(0 \cdot 88-2 \cdot 88)$ & $0 \cdot 121$ \\
\hline Standard deviation of random effects & $0 \cdot 40(0 \cdot 25-0 \cdot 63)$ & \\
\hline Interclass correlation coefficient (rho) & $0 \cdot 05(0 \cdot 02-0 \cdot 11)$ & \\
\hline
\end{tabular}

OR, Odds ratio; CI, confidence interval.

association between enhanced biosecurity and colonization at the time of thinning and the subsequent attenuation of this effect at the time of total depopulation could indicate that enhanced biosecurity is more effective at delaying than preventing colonization.

\section{Thinning practice}

It is likely that thinning itself can be considered to directly counter the protective effects of enhanced biosecurity. That practice is at least in part responsible for the attenuation of the protective effect of biosecurity by the time of depopulation, as the role of thinning as a risk factor for infection has been well established $[15,18]$ and is also identified in this study: flocks that had been partially depopulated (thinned) experienced a twofold higher odds of colonization at depopulation than batches in which partial depopulation had not been practised. The fact that thinning was applied to $90 \%$ of batches included in this study and the strong financial motivation of the practice suggest that ceasing it completely may not be feasible in the UK, since it would require additional investments in new poultry houses.

Our findings, supporting a protective effect of farm hygiene measures on batch colonization, are in agreement with previous studies in The Netherlands [25], the UK [26] and Denmark [27]. Other studies in countries such as Norway and Iceland [28] indicate an unpredictable effect of hygienic measures on farms and report conflicting evidence.

\section{Other risk factors}

There was evidence of an association between the number of empty days between flocks and colonization: batches for which the shed had been kept empty less than a week appear to be at lower risk $(83.0 \%)$ of colonization. The batches processed after a prolonged empty period of $>21$ days had a $42.0 \%$ increase in risk compared to a period of 8-14 days. Previous studies have also identified an association between the 
Table 4. Results of random-effects logistic regression (regression model 2 'risk factors within high biosecurity farms model') investigating the contribution of selected factors in model farms to Campylobacter spp. colonization (defined as $>123000$ c.f.u.Ig in pooled caecal samples). Results from a total of 1510 batches sampled between 16 October 2011 and 31 August 2013 in 16 farms with enhanced biosecurity included in the UK poultry study on enhanced biosecurity and Campylobacter colonization, UK, 2011-2013

\begin{tabular}{|c|c|c|}
\hline Factors & OR $(95 \% \mathrm{CI})$ & $P$ value \\
\hline \multicolumn{3}{|l|}{ Harvest occasion } \\
\hline Thinning & $1 \cdot 00$ & \multirow[t]{2}{*}{$<0 \cdot 001$} \\
\hline Depopulation & $3 \cdot 30(2 \cdot 61-4 \cdot 18)$ & \\
\hline \multicolumn{3}{|l|}{ Type of hybrid } \\
\hline Cobb 500 & $0.53(0.31-0.89)$ & $0 \cdot 017$ \\
\hline Cobb 500 \& Ross 308 & $3 \cdot 23(1 \cdot 08-9 \cdot 63)$ & $0 \cdot 035$ \\
\hline JA 87 & $1.27(0.42-3 \cdot 85)$ & \multirow[t]{2}{*}{$0 \cdot 670$} \\
\hline Ross 308 & 1 & \\
\hline Ross 708 & $0 \cdot 68(0 \cdot 35-1 \cdot 33)$ & $0 \cdot 266$ \\
\hline \multicolumn{3}{|l|}{ Empty days } \\
\hline Up to 1 week & $0.69(0.49-0.96)$ & \multirow[t]{2}{*}{$0 \cdot 026$} \\
\hline 1-2 weeks & 1 & \\
\hline $2-3$ weeks & $0 \cdot 90(0.57-1 \cdot 42)$ & $0 \cdot 645$ \\
\hline$>3$ weeks & $3.03(1 \cdot 14-8 \cdot 07)$ & $0 \cdot 027$ \\
\hline \multicolumn{3}{|l|}{ Days to depopulation } \\
\hline $1-3$ days & $0.57(0 \cdot 36-0 \cdot 90)$ & $0 \cdot 016$ \\
\hline 4-6 days & $0 \cdot 85(0 \cdot 60-1 \cdot 18)$ & \multirow[t]{2}{*}{$0 \cdot 337$} \\
\hline 7-9 days & 1 & \\
\hline 10-12 days & $0 \cdot 85(0 \cdot 53-1 \cdot 38)$ & $0 \cdot 521$ \\
\hline 13-18 days & $0.48(0 \cdot 24-0.99)$ & $0 \cdot 047$ \\
\hline \multicolumn{3}{|l|}{ Sampling period } \\
\hline 16 Oct. -30 Nov. 2011 & $0 \cdot 74(0 \cdot 36-1 \cdot 51)$ & $0 \cdot 414$ \\
\hline 1 Dec.-29 Feb. 2012 & $0 \cdot 86(0.54-1 \cdot 37)$ & $0 \cdot 526$ \\
\hline 1 Mar.-31 May 2012 & $1.99(1.29-3.08)$ & $0 \cdot 002$ \\
\hline 1 June-30 Aug. 2012 & $7 \cdot 74(4 \cdot 76-12 \cdot 59)$ & $<0 \cdot 001$ \\
\hline 1 Sept. -30 Nov. 2012 & $0.92(0.59-1.42)$ & \multirow[t]{2}{*}{$0 \cdot 694$} \\
\hline 1 Dec.-28 Feb. 2013 & 1 & \\
\hline 1 Mar.-31 May 2013 & $1 \cdot 13(0.73-1 \cdot 76)$ & $0 \cdot 581$ \\
\hline 1 June-30 Aug. 2013 & $4 \cdot 18(2 \cdot 62-6 \cdot 69)$ & $<0 \cdot 001$ \\
\hline Constant & $0 \cdot 61(0 \cdot 37-1 \cdot 01)$ & \multirow[t]{3}{*}{$0 \cdot 053$} \\
\hline Standard deviation of random effects & $0 \cdot 51(0 \cdot 29-0 \cdot 90)$ & \\
\hline Interclass correlation coefficient (rho) & $0.07(0.03-0.20)$ & \\
\hline
\end{tabular}

OR, Odds ratio; CI, confidence interval.

length of the empty period between flocks [29] and potential for re-infection from the contaminated environment [30]. A prolonged empty period between flocks increases the probability of the shed becoming contaminated from the environment by the time new birds are introduced.

A short period (1-3 days) between thinning and depopulation was also associated with a lower risk of colonization compared to batches for which the period between thinning and depopulation was 7-9 days. The results support the existence of differences in Campylobacter colonization between the hybrids; these may be due to a biological characteristic of the birds, differences in the length of the cycle, growth rates, age of harvest or unmeasured factors associated with the type of hybrid such as diet or specific husbandry practices. Previous experimental studies showed little impact of broiler breed to the susceptibility of chickens to $C$. jejuni colonization, but it has been reported that in fast-growing breeds the inflammatory response remains elevated for longer [31].

As expected, the risk of colonization exhibits a strong seasonality, with batches raised during winter at significantly lower risk of colonization. The effect of season on colonization of batches has been extensively reported and tentatively attributed to the ability 
Table 5. Results of random-effects logistic regression (regression model 3 'thinning practice model') investigating the effect of partial depopulation (thinning) on Campylobacter spp. colonization (defined as $>123000$ c.f.u.Ig in pooled caecal samples) at depopulation. Results from a total of 888 batches sampled between 16 October 2011 and 31 August 2013 included in the UK poultry study on enhanced biosecurity and Campylobacter colonization; UK, 2011-2013

\begin{tabular}{|c|c|c|}
\hline Factors & OR $(95 \% \mathrm{CI})$ & $P$ value \\
\hline \multicolumn{3}{|l|}{ Practice of thinning } \\
\hline The flock had not been partially depopulated (78 batches) & $1 \cdot 00$ & $0 \cdot 004$ \\
\hline The flock had been partially depopulated (thinned) (810 batches) & $2 \cdot 43(1 \cdot 34-4 \cdot 42)$ & \\
\hline \multicolumn{3}{|l|}{ Sampling period } \\
\hline 16 Oct. -30 Nov. 2011 & $0 \cdot 63(0 \cdot 20-1 \cdot 37)$ & $0 \cdot 245$ \\
\hline 1 Dec. -29 Feb. 2012 & $0.53(0 \cdot 30-0 \cdot 93)$ & $0 \cdot 028$ \\
\hline 1 Mar.-31 May 2012 & $2 \cdot 52(1 \cdot 40-4 \cdot 43)$ & $0 \cdot 001$ \\
\hline 1 June-30 Aug. 2012 & $4 \cdot 90(2 \cdot 60-9 \cdot 21)$ & $<0 \cdot 001$ \\
\hline 1 Sept. -30 Nov. 2012 & $0 \cdot 88(0 \cdot 50-1 \cdot 49)$ & $0 \cdot 624$ \\
\hline 1 Dec. -28 Feb. 2013 & $1 \cdot 00$ & \\
\hline 1 Mar.-31 May 2013 & $1.69(0.90-2.93)$ & $0 \cdot 064$ \\
\hline 1 June-30 Aug. 2013 & $1 \cdot 57(0 \cdot 90-2 \cdot 71)$ & $0 \cdot 101$ \\
\hline Constant & $0 \cdot 66(0 \cdot 30-1 \cdot 36)$ & $0 \cdot 263$ \\
\hline Standard deviation of random effects & $0 \cdot 47(0 \cdot 26-0 \cdot 85)$ & \\
\hline Interclass correlation coefficient (rho) & $0 \cdot 06(0 \cdot 02-0 \cdot 18)$ & \\
\hline
\end{tabular}

OR, Odds ratio; CI, confidence interval.

Table 6. Results of a conditional logistic regression (regression model 4 'A company's five-farms model') of enhanced biosecurity and other factors on batch colonization (defined as $>123000$ c.f.u.lg in pooled caecal samples). Results from a total of 712 batches sampled between 16 October 2011 and 31 August 2013 included in the UK poultry study on enhanced biosecurity and Campylobacter colonization, UK, 2011-2013

\begin{tabular}{lll}
\hline \hline Factors & OR $(95 \% \mathrm{CI})$ & $P$ value \\
\hline $\begin{array}{l}\text { Biosecurity } \\
\quad \text { Standard (control farms 1) }\end{array}$ & 1 & \\
$\quad \begin{array}{l}\text { Enhanced (model farms) } \\
\text { Harvest occasion }\end{array}$ & $0 \cdot 32(0 \cdot 20-0 \cdot 52)$ & $<0 \cdot 001$ \\
$\quad$ & 1 & \\
$\quad$ Thinning & $2 \cdot 87(2 \cdot 00-4 \cdot 12)$ & $<0 \cdot 001$ \\
$\quad \begin{array}{l}\text { Depopulation } \\
\text { Sampling period }\end{array}$ & $0 \cdot 71(0 \cdot 30-1 \cdot 68)$ & $0 \cdot 437$ \\
16 Oct.-30 Nov. 2011 & $0 \cdot 62(0 \cdot 31-1 \cdot 25)$ & $0 \cdot 178$ \\
1 Dec.-29 Feb. 2012 & $6 \cdot 99(3 \cdot 63-13 \cdot 46)$ & $<0 \cdot 001$ \\
1 Mar.-31 May 2012 & $19 \cdot 90(9 \cdot 21-43 \cdot 00)$ & $<0 \cdot 001$ \\
1 June-30 Aug. 2012 & $1 \cdot 08(0 \cdot 57-2 \cdot 05)$ & $0 \cdot 813$ \\
1 Sept.-30 Nov. 2012 & 1 & \\
1 Dec.-28 Feb. 2013 & $2 \cdot 22(1 \cdot 19-4 \cdot 13)$ & $0 \cdot 012$ \\
1 Mar.-31 May 2013 & $5 \cdot 90(3 \cdot 05-11 \cdot 42)$ & $<0 \cdot 001$ \\
1 June-30 Aug. 2013 & & \\
\hline \hline
\end{tabular}

OR, Odds ratio; CI, confidence interval.

of Campylobacter spp. to decay or transform in cold conditions into a viable but non-culturable state, which has the potential for lengthy survival. Other potential seasonal effects include flies as potential carriers $[32,33]$ and seasonal changes in farm practices $[34,35]$.

Differences that are not explained by the studied factors in the actual counts of campylobacters might be attributed to additional factors such as the dose of exposure, effectiveness of the transmission, the time elapsed from infection to slaughter and individual susceptibility including the influence of stress factors.

The estimated PAFs suggest that one third of highly colonized batches could be prevented if all farms enhanced their biosecurity to similar standards of the model farms in this study. A similar effect could be achieved if none of the crops sent to the slaughterhouse had been subject to previous thinning. The potential effect of raising only hybrid types identified to be of low risk was estimated to be between a $4 \cdot 0 \%$ and $27 \cdot 0 \%$ reduction in the proportion of highly colonized batches. The expected effects of interventions (PAFs) are based on estimates obtained from the study batches and assume causal association between exposure and colonization. Extrapolations should, however, be made with caution as they provide an indication of the extent to which interventions at farm level can mitigate Campylobacter colonization in broiler chickens and as a result human exposure to Campylobacter spp. Preventing high colonization in one third of chicken batches by improving biosecurity 

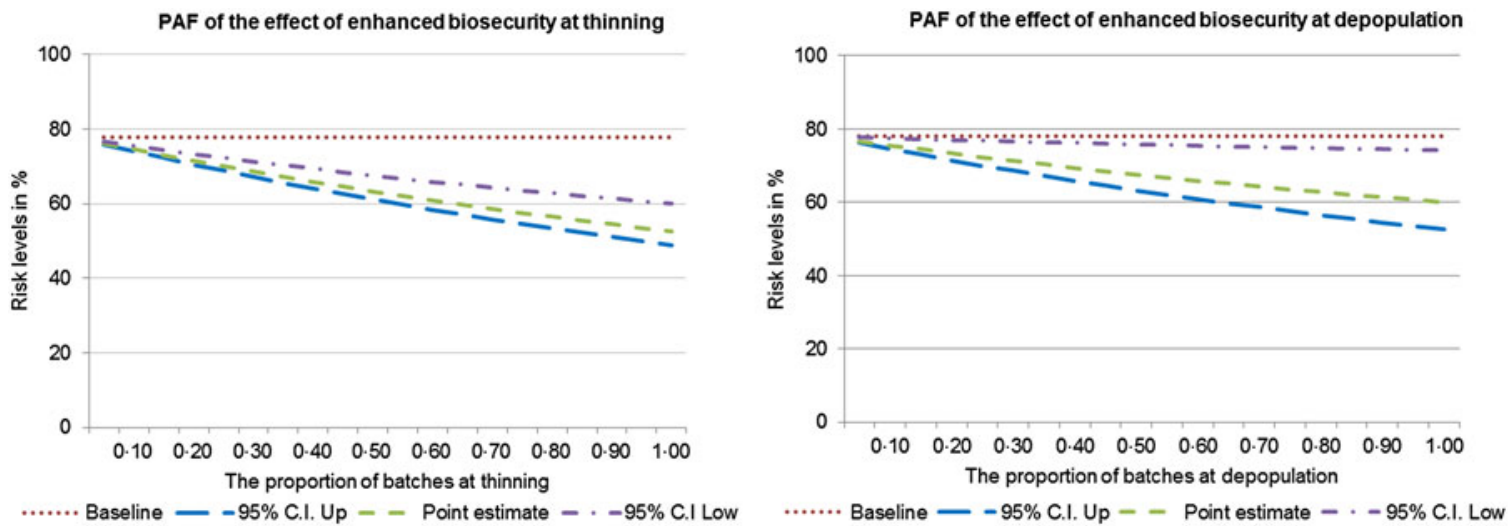

Fig. 3. Population attributable fraction (PAF) of the effect of enhanced biosecurity on batch colonization at thinning and depopulation.

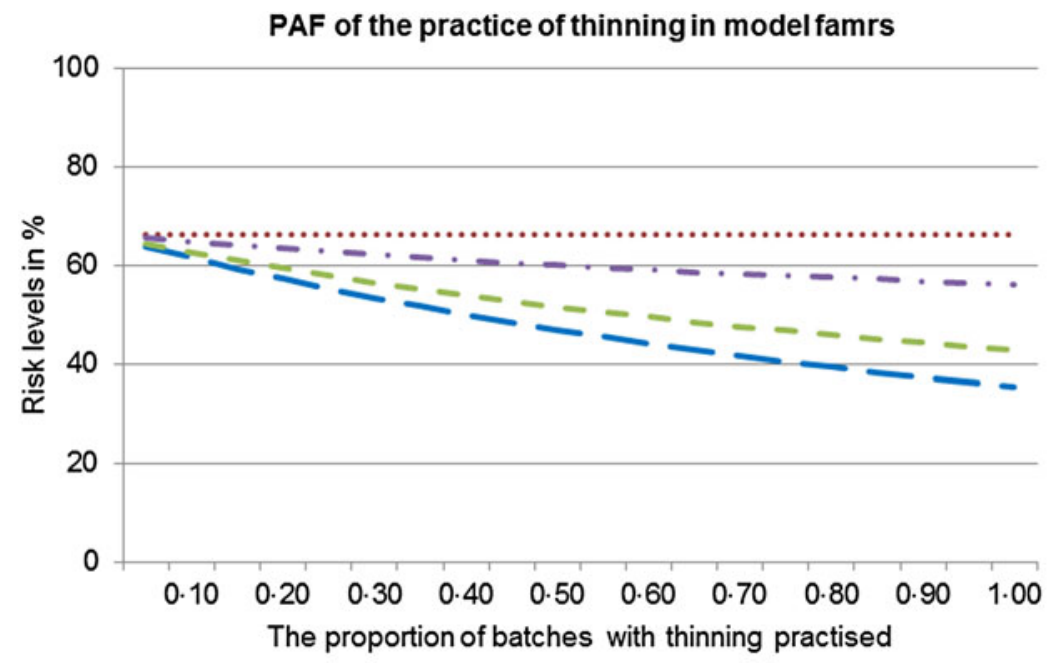

Baseline - $-95 \%$ C.I. Up - - Point estimate - - $-95 \%$ C.I. Low

Fig. 4. Population attributable fraction (PAF) of the effect of the practice of thinning on batch colonization in model farms.
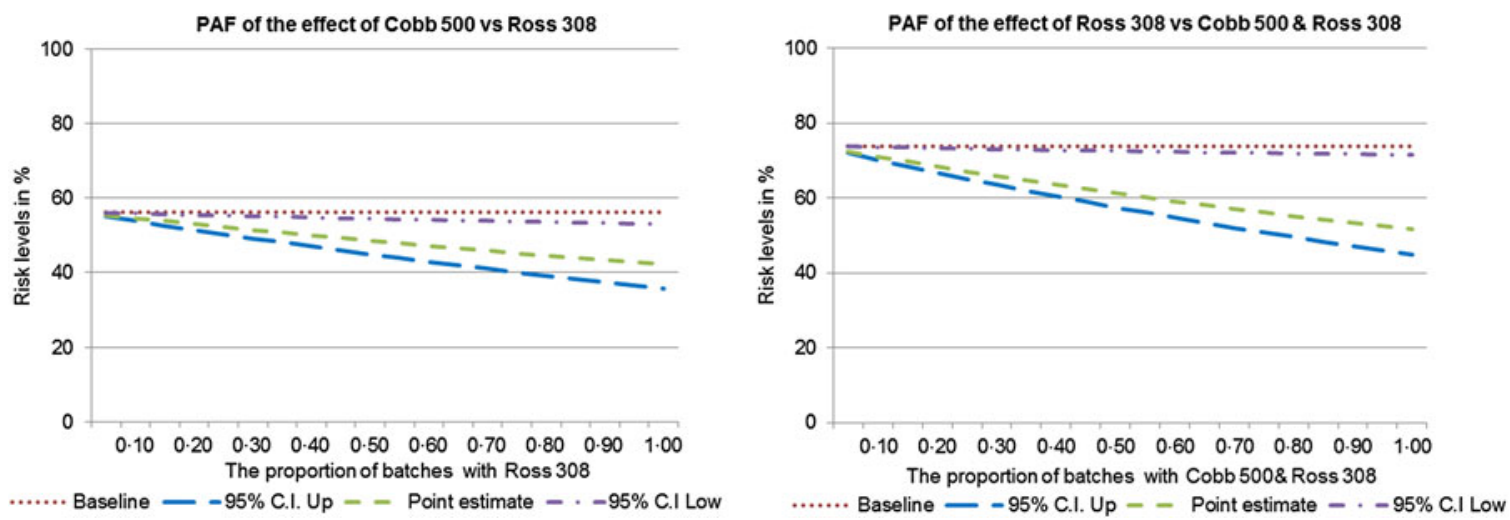

Fig. 5. Population attributable fraction (PAF) of the effect of hybrids on batch colonization in model farms. 
has the potential to avert $7-10 \%$ of human cases attributed to consumption of chicken meat and reduce the number of cases attributed to the chicken reservoir as whole by about one quarter, assuming that the EFSA source attribution model [9] is correct. A number of limitations of the study should be acknowledged. Although farms were recruited with the aim of trying to avoid obvious departures from established poultry production practices, farm selection was not carried out probabilistically and selection bias as a result of systematic differences between the study farms and the general population of UK farms cannot be ruled out. Similarly, control farms were not selected probabilistically and differences with model farms, other than the level of biosecurity, cannot be excluded. Lack of information on farm of origin for the main group of control batches prevented us from accounting for potential within-farm clustering, and within-company clustering was considered instead. We have not evaluated the performance of different laboratories in the study. However, we believe that the use of a standardized and well-known methodology reduces potential variation between the laboratories. The batches positive in caeca do not necessarily correlate perfectly with batches positive in neck skin. However, high colonization in caeca is expected to result in high positive results in neck skin. The PAF values are based on estimates of strength of association and of frequency of exposure obtained from poultry batches grown in a non-probabilistic sample of farms and under the assumption of a causal relationship between exposure and colonization. The values could be interpreted as an a priori expectation of the likely effect of potential interventions. The formal assessment of effectiveness of different interventions would require a randomized control trial. Despite these limitations, it seems unlikely that the main findings of the study are due to these potential biases.

This study provides empirical evidence of the potential of enhancing biosecurity as a means of reducing the proportion of heavily contaminated batches sent to slaughterhouses and eventually the proportion of heavily contaminated chickens at retail. It also shows a potential to mitigate the risk of heavily contaminated chicken reaching the consumer by enhancing biosecurity in combination with other measures further along the poultry chain maximizing the effectiveness of intervention. The existence of an interaction between enhanced biosecurity and thinning by which one modifies the effect of the other implies that potential interventions should consider both simultaneously. The association between breed and risk of colonization should be further explored as it is possible that factors other than the characteristics of the birds are responsible.

Even though Campylobacter is referred to as the top pathogen associated with foodborne disease in the EU there are no mandatory requirements for monitoring foodstuffs on microbiological criteria as those contained in Commission Regulation (EC) No. 2073/ 2005 for other foodborne pathogens, including Salmonella. There are indications that the controls applied for Salmonella would not necessarily correlate with a decrease in the prevalence of Campylobacter spp. [36]. Studies in The Netherlands [37] and Nordic countries [38] propose the implementation of threshold levels for batch colonization at the end of slaughter. The results of this study justify the implementation of an intervention study to confirm and quantify the impact of combined changes to biosecurity and thinning including monitoring beyond the abattoir.

\section{SUPPLEMENTARY MATERIAL}

For supplementary material accompanying this paper visit https://doi.org/10.1017/S095026881600251X.

\section{ACKNOWLEDGEMENTS}

We thank the Food Standards Agency for funding and valuable comments together with other members of the Joint Working Group on Campylobacter. The companies Moy Park, PD Hook and 2 Sisters Food Group initiated and implemented the project and provided raw data and valuable advice. We also thank Jane Downes and Joey Ellis-Iversen for valuable comments and advice and to all those who were involved in logistics, sample collection and laboratory analyses.

This work was supported by the Food Standards Agency (project FS101114).

\section{DECLARATION OF INTEREST}

None.

\section{REFERENCES}

1. European Food Safety Authority - European Centre for Disease Prevention and Control. The European Union summary report on trends and sources of zoonoses, 
zoonotic agents and food-borne outbreaks in 2013. EFSA Journal 2015; 13: 1-165.

2. European Food Safety Authority, Panel on Biological Hazards (BIOHAZ). Scientific opinion on Campylobacter in broiler meat production: control options and performance objectives and/or targets at different stages of the food chain. EFSA Journal 2011; 9: 1-141.

3. Heymann D. Control of Communicable Diseases Manual, 19th edn. Washington, DC: American Public Health Association, 2008, pp. 94-98.

4. Harris NV, Weiss NS, Nolan CM. The role of poultry and meats in the etiology of Campylobacter jejunilcoli enteritis. American Journal of Public Health 1986; 76 : 407-411.

5. Bull SA, et al. Flock health indicators and Campylobacter spp. in commercial housed broilers reared in Great Britain. Applied and Environmental Microbiology 2008; 74: 5408-5413.

6. McDowell S, et al. Campylobacter spp. in conventional broiler flocks in Northern Ireland: Epidemiology and risk factors. Preventive Veterinary Medicine 2008; 84: 261-276.

7. Sheppard SK, et al. Campylobacter genotyping to determine the source of human infection. Clinical Infectious Diseases 2009; 48: 1072-1078.

8. Muellner P, et al. Molecular-based surveillance of campylobacteriosis in New Zealand-from source attribution to genomic epidemiology. Eurosurveillance 2013; 18: pii $=20365$.

9. European Food Safety Authority, Panel on Biological Hazards (BIOHAZ). Scientific opinion on quantification of the risk posed by broiler meat to human campylobacteriosis in the EU. EFSA Journal 2010; 8: 1-89.

10. European Food Safety Authority. Analysis of the baseline survey on the prevalence of Campylobacter in broiler batches and of Campylobacter and Salmonella on broiler carcasses in the EU, 2008 Part A: Campylobacter and Salmonella prevalence estimates. EFSA Journal 2010; 8: 1-99.

11. Bull SA, et al. Sources of Campylobacter spp. colonizing housed broiler flocks during rearing. Applied and Environmental Microbiology 2006; 72: 645-652.

12. Ellis-Iversen $\mathbf{J}$, et al. Persistent environmental reservoirs on farms as risk factors for Campylobacter in commercial poultry. Epidemiology and Infection 2012; 140: 916-924.

13. Shane SM, Montrose MS, Harrington KS. Transmission of Campylobacter jejuni by the housefly (Musca domestica). Avian Diseases 1985; 29: 384-391.

14. Allen V, et al. Sources and spread of thermophilic Campylobacter spp. during partial depopulation of broiler chicken flocks. Journal of Food Protection 2008; 71: 264-270.

15. Newell D, et al. Biosecurity-based interventions and strategies to reduce Campylobacter spp. on poultry farms. Applied and Environmental Microbiology 2011; 77: 8605-8614.

16. Shreeve J, et al. The carry-over of Campylobacter isolates between sequential poultry flocks. Avian Diseases 2002; 46: 378-385.
17. Ellis-Iversen $\mathbf{J}$, et al. Risk factors for Campylobacter colonisation during rearing of broiler flocks in Great Britain. Preventive Veterinary Medicine 2009; 89: 178-184.

18. Wagenaar JA, et al. Phage therapy reduces Campylobacter jejuni colonization in broilers. Veterinary Microbiology 2005; 109: 275-283.

19. Stern NJ, et al. Bacteriocins reduce Campylobacter jejuni colonization while bacteria producing bacteriocins are ineffective. Microbial Ecology in Health and Disease 2008; 20: 74-79.

20. Willis W, Reid L. Investigating the effects of dietary probiotic feeding regimens on broiler chicken production and Campylobacter jejuni presence. Poultry Science 2008; 87: 606-611.

21. Buckley AM, et al. Evaluation of live-attenuated salmonella vaccines expressing Campylobacter antigens for control of $C$. jejuni in poultry. Vaccine 2010; 28: 1094-1105.

22. Zhang J, Yu KF. What's the relative risk? A method of correcting the odds ratio in cohort studies of common outcomes. Journal of the American Medical Association 1998; 280: 1690-1691.

23. Potter TJ, et al. Risk factors for clinical endometritis in postpartum dairy cattle. Theriogenology 2010; 74: 127-134.

24. Williamson DF. The population attributable fraction and confounding: buyer beware. International Journal of Clinical Practice 2010; 64: 1019-1023.

25. Van de Giessen A, et al. Epidemiological study on risk factors and risk reducing measures for Campylobacter infections in Dutch broiler flocks. Epidemiology and Infection 1996; 117: 245-250.

26. Gibbens $\mathbf{J}$, et al. A trial of biosecurity as a means to control Campylobacter infection of broiler chickens. Preventive Veterinary Medicine 2001; 48: 85-99.

27. Rosenquist $\mathbf{H}$, et al. Campylobacter contamination and the relative risk of illness from organic broiler meat in comparison with conventional broiler meat. International Journal of Food Microbiology 2013; 162: 226-230.

28. Wagenaar J, Mevius D, Havelaar A. Campylobacter in primary animal production and control strategies to reduce the burden of human campylobacteriosis. Scientific and Technical Review. World Organisation for Animal Health (OIE) 2006; 25: 581-594.

29. Wedderkopp A, Rattenborg E, Madsen M. National surveillance of Campylobacter in broilers at slaughter in Denmark in 1998. Avian Diseases 2000; 44: 993-999.

30. Chowdhury S, et al. Risk factors for Campylobacter infection in Danish broiler chickens. Poultry Science 2012; 91: 2701-2709.

31. Humphrey S, et al. Campylobacter jejuni is not merely a commensal in commercial broiler chickens and affects bird welfare. MBio 2014; 5: e01364-14.

32. Hald B, Sommer HM, Skovgård H. Use of fly screens to reduce Campylobacter spp. introduction in broiler houses. Emerging Infectious Diseases 2007; 13: 1951-1953.

33. Jorgensen F, et al. Influence of season and geography on Campylobacter jejuni and $C$. coli subtypes in 
housed broiler flocks reared in Great Britain. Applied and Environmental Microbiology 2011; 77: 3741-3748.

34. Newell D, Fearnley C. Sources of Campylobacter colonization in broiler chickens. Applied and Environmental Microbiology 2003; 69: 4343-4351.

35. Powell L, et al. The prevalence of Campylobacter spp. in broiler flocks and on broiler carcases, and the risks associated with highly contaminated carcases. Epidemiology and Infection 2012; 140: 2233-2246.

36. Hue O, et al. Prevalence of and risk factors for Campylobacter spp. contamination of broiler chicken carcasses at the slaughterhouse. Food Microbiology 2010; 27: 992-999.
37. Swart AN, Mangen MJJ, Havelaar AH. RIVM Report: Microbiological criteria as a decision tool for controlling Campylobacter in the broiler meat chain. RIVM, NL, 2013 (http://www.betelgeux.es/images/files/ Externos/Campylobacter.pdf). Accessed 22 March 2016.

38. Nauta M. Establishment of risk based microbiological criteria in the Nordic countries: a case study on Campylobacter in broiler meat. National Food Institute, Technical University of Denmark, 2013 (http://www. food.dtu.dk/ /media/Institutter/Foedevareinstituttet/Publi kationer/Pub-2013/Report-microbiological_criteria.ashx). Accessed 22 March 2016. 